ORIGINAL ARTICLE

\title{
Colectomy in Patients with Colonic Carcinoma: Laparoscopic Versus Open Methods
}

\author{
Bassam Rabieh Mousa ${ }^{\text {* }}$, Alaa Mohamed Khalil ', Wael Lotfy Mokhtar', Mohamed Ibrahim \\ Abdelhamid ', Ramadan Mahmoud Ali', Hassan Rabieh Ashour' \\ 'General Surgery departments, Faculty of medicine, Zagazig University, Egypt
}

\section{*Corresponding author:}

Bassam Rabieh Mahmoud Mousa

Assistant Lecturer of General Surgery

Faculty of medicine, Zagazig University, Egypt

$\begin{array}{ll}\text { Submit Date } & \text { 4-3-2019 } \\ \text { Revise Date } & 13-3-2019 \\ \text { Accept Date } & 14-3-2019\end{array}$

\begin{abstract}
Background: colon cancer is one of the most common cancers all over the world. There are many methods for surgical removal of the cancer as open conventional colectomy and laparoscopic colectomy. The aim of this study is to compare between the two methods to establish the advantages and disadvantages of laparoscopic colectomy in comparison to open colectomy. Methods: Patients were divided into 2 groups according to type of surgical interference. Group 1: included "15 patients" comprised those who had colonic carcinoma with laparoscopic intervention. Group 2: included "15 patients" comprised those who had colonic carcinoma with open surgical intervention. This study included patients with colonic carcinoma were admitted to Zagazig University Hospitals. Patients were collected in the period from December 2016 to December 2018. Results: the results showed that there are no significant differences between laparoscopic colectomy and open colectomy. Laparoscopic colectomy showed advantages over open colectomy in terms of short hospital stay $(\mathrm{P}=0.02)$, rapid recovery, early return to work and good oncological outcomes. Conclusion: Laparoscopic colectomy can be performed with good technical efficiency, quick recovery of bowel function, and mild disability, less operative blood loss, less operative trauma and shorter hospital stay. The short-term oncologic results of laparoscopic colectomy seem to be acceptable and comparable with conventional methods. We recommend using Laparoscopic colectomy in colonic carcinoma as a gold standard in our hospital to get the aforementioned advantages.

Keywords: Laparoscopic Colectomy; Open colectomy; Cancer Colon.
\end{abstract}

\section{INTRODUCTION}

olon cancer is regarded one of the most
common tumors all over the world.
Surgical resection of the primary site with
adequate safety margins and lymphadenectomy
offers the best chance of long-standing disease-
free and whole survival. Traditional open
colectomy is regarded the gold standard for
both malignant and benign diseases. Minimally
invasive laparoscopically assisted surgery was
first considered in 1990 for patients undergoing
colectomy for cancer [1].
Using the laparoscopic approach, the surgeon
uses tools through port sites to mobilize the
section of colon to be removed, avoiding a
large laparotomy incision. Usually, two to three 5-mm port sites and one 10-mm or 12-mm port site are created. Although this procedure often requires a small incision to remove the diseased portion of the colon, the incision is much smaller, causing less postoperative pain and shortening the hospital stay and rapid patient recovery. This leads to a faster return to activities of daily living for the patient [2].

Great advances have been made in laparoscopic surgery during the past two decades, from diagnostic procedures to colon resections. Nowadays laparoscopic approach is considered safe and good choice for both patient and surgeon with better outcomes [2].

This study focus on comparison between laparoscopic and open conventional recection 
of colonic carcinoma in different parts of the colon. It is considered the first study dealing with this subject at Zagazig university hospitals.

\section{Objectives:}

To compare efficacy between laparoscopic and open colostomy in patients with colonic carcinoma. Also, to evaluate short-term and postoperative outcome of both approaches. Finally, to evaluate the efficacy of either approach in radicality of resection on pathological bases.

\section{PATIENTS AND METHODS}

A total of 30 patients attending Zagazig University hospital from December 2016 to December 2018 included in a prospective study. Written informed consent was obtained from all participants and the study was approved by the research ethical committee of Faculty of Medicine, Zagazig University. The work has been carried out in accordance with The Code of Ethics of the World Medical Association (Declaration of Helsinki) for studies involving humans. Patients were divided into two groups according to type of surgical interference.

Group 1: included "15 patients" comprised those who had colonic carcinoma with laparoscopic intervention.

Group 2: included "15 patients" comprised those who had colonic carcinoma with open surgical intervention.

\section{Inclusion criteria:}

Patients' Age between 18 years and 80 years at both genders with a final diagnosis of colonic carcinoma. Operable patients of colonic carcinoma. Also, patients who will follow up constantly after operation and cooperative patients.

\section{Exclusion criteria:}

Inoperable patients with multicenteric colonic carcinoma and patients who are unavailable during study. Also patients who have contraindications for laparoscopy.

\section{Surgical techniques:}

\section{Preoperative preparation:}

Preoperative evaluation was done through laboratory investigations as (CBC- PT, PTT,
INR - CEA Tumor marker - Liver \& Kidney function tests - Random Blood glucose level HCV \& HBV viral markers). Also patients had colonoscopy with biopsy for histopathology and pelvi-abdominal Computed tomography. Patients were consented for surgery. Bowel preparation was done. Also, Foley's catheter and nasogastric tube were inserted. Intravenous antibiotics at induction of anesthesia. Sequential compression stockings and administration of subcutaneous low molecular weight heparin for venous thrombosis prophylaxis.

\section{Open colectomy:}

General anesthesia with endotracheal intubation was induced with the patient in the supine position, then midline exploratory incision was done till peritoneum. Evaluation of the liver and peritoneum was done for exclusion of any metastasis or signs of inoperability, then detection of the site of the tumor with resection according to the site as follow: right hemicolectomy for cancer caecum and ascending colon, extended right hemicolectomy for hepatic flexure mass. Transverse colectomy for masses at transverse colon, left hemicolectomy for left sided tumors and extended left hemicolectomy for splenic flexure masses. Finally, Sigmoidectomy for sigmoid masses. Resection anastomosis was done, Lavage of the abdomen and closure of the abdominal incisions in layers with intraabdminal tube drains.

Intra operative and post-operative complications were recorded

\section{Laparoscopic colectomy:}

After induction of general anesthesia and endotracheal intubation, the patient was properly positioned according to the operated site of the tumor. Pneumoperitoneum creation via $10 \mathrm{~mm}$ subumbilical safety trocar. Trocars are placed according to the site of the tumor. Inspection of the whole abdomen was done at first to exclude liver metastasis or intraperitoneal Mets of the tumor then we started the procedure. There are two approaches for resection of the right or left cancer colon, medial and lateral approaches. We used the 
medial approach that requires ligation of the lymphovascular bundle first then free the colon from its peritoneal attachments. After that hemostasis was done and intracorporeal or extracorporeal anastomosis was done. Extraction of the tumor through widening one of the ports or via pfannestiel incision. Irrigation of the peritoneal space and port site, intra peritoneal tube drains were put, removing trocars with deflation of $\mathrm{Co} 2$. Closure of the port sites with staples.

Intra operative and post-operative complications were recorded

\section{Postoperative care:}

Intravenous antibiotics are postoperatively continued. Oral fluid intake is started three days after surgery then advanced to a regular diet as the patient tolerates feeding. Early ambulation is instructed to avoid DVT.

\section{RESULTS}

\section{Demography of the patients:}

This prospective study was conducted on 30 patients presented with colonic carcinoma (15 patients had operated by open colectomy and 15 patients had operated by laparoscopic colectomy) came to the outpatient clinic of Zagazig University hospitals between December 2016 to December 2018.

Patients undergoing laparoscopic surgery were marginally younger (mean 52 vs. 62 years, $\mathrm{p}=0.007$ ). There was no significant difference in gender distribution between the two groups, while there was a statistical significant difference between the study groups in age as open colectomy patients had older age than laparoscopic colectomy patients.

\section{Site of operation}

All sites of the colon were operated e.g. caecum, right colon, hepatic flexure, transverse colon, left colon and sigmoid colon. There was no statistical significant difference between the study groups regarding the site of operation.

Number of affected lymph nodes:

There was no statistical significant difference between the study groups regarding number of affected lymph nodes.

\section{Intraoperative complications:}

In laparoscopic colectomy group, 11 patients had no complications intraoperative, 2 patients had bleeding and 2 patients only had left ureteric injury during laparoscopic Sigmoidectomy. While in open colectomy, 13 patients had no intraoperative complications and 2 patients had bleeding during operation. There was no statistical significant difference between the study groups regarding intraoperative complications $(\mathrm{P}=0.6)$.

\section{Postoperative complications:}

In Laparospic colectomy group, 15 patients had no post-operative complications while in open colectomy group, 8 patients had post-operative complications in the form of burst abdomen, faecal fistula and incisional hernia $(\mathrm{P}=0.006)$. There was a statistical significant difference between study groups in postoperative complications as none of Laparoscopic colectomy patients had postoperative complications.

\section{Operation time:}

In laparoscopic colectomy group, the mean operation time was $(145 \pm 19 \mathrm{~min}$.) about 10 min. longer in duration than operation time at open colectomy that was $(135 \pm 17)$. There was no statistical significant difference between study groups regarding operation time $(\mathrm{P}=0.1)$.

\section{Length of hospital stay:}

In laparoscopic colectomy the mean length of hospital stay was 5.4 days in comparison to that of open colectomy that was 7.9 days. There was a statistical significant difference between studied groups in Length of hospital stay as Open colectomy patients had more hospital days than Laparoscopic colectomy patients $(\mathrm{P}=0.02)$.

\section{Amount of blood loss}

In laparoscopic colectomy group, the amount of blood loss mean was $306 \mathrm{ml}$. in comparison to that op open colectomy that was $320 \mathrm{ml}$. There was no statistical significant difference between study groups regarding amount of blood loss.

\section{Survival of the studied patients}

There was no statistical significant difference between study groups regarding Survival rate $(\mathrm{P}=0.4)$.

Need for reoperation 
There was no statistical significant difference reoperation rate $(\mathrm{p}=0.1)$. between study groups regarding need for

Table 1.Number of affected lymph nodes in the studied patients

\begin{tabular}{|c|c|c|c|c|c|c|}
\hline \multirow[t]{2}{*}{ Number of affected lymph nodes } & \multicolumn{2}{|c|}{$\begin{array}{c}\text { Open colectomy } \\
(n=15)\end{array}$} & \multicolumn{2}{|c|}{$\begin{array}{c}\text { Laparoscopic } \\
\text { colectomy }(n=15)\end{array}$} & \multirow[t]{2}{*}{$\mathbf{X}^{2}$} & \multirow[t]{2}{*}{$\mathbf{p}$} \\
\hline & No. & $\%$ & No. & $\%$ & & \\
\hline None & 7 & 46.6 & 5 & 33.3 & 0.5 & 0.4 \\
\hline One lymph node & 4 & 26.7 & 6 & 40.0 & 0.6 & 0.4 \\
\hline >one lymph node & 4 & 26.7 & 4 & 26.7 & 0.001 & 0.99 \\
\hline
\end{tabular}

This table shows that there was no statistical significant difference between study groups regarding number of affected lymph nodes.

Table 2. Intraoperative complications in the studied patients:

\begin{tabular}{|c|c|c|c|c|c|c|}
\hline \multirow{2}{*}{$\begin{array}{c}\text { Intraoperative } \\
\text { complications }\end{array}$} & \multicolumn{2}{c|}{$\begin{array}{c}\text { Open colectomy } \\
(\mathbf{n}=\mathbf{1 5})\end{array}$} & \multicolumn{2}{c|}{$\begin{array}{c}\text { Laparoscopic } \\
\text { colectomy }(\mathbf{n = 1 5})\end{array}$} & $\mathbf{X}^{\mathbf{2}}$ & \\
\hline & $\mathbf{N o}$ & $\mathbf{\%}$ & $\mathbf{N o .}$ & $\mathbf{p}$ & & \\
\hline No complications & 13 & 86.7 & 11 & 73.4 & 0.001 & 0.6 \\
\hline Bleeding & 2 & 13.3 & 2 & 13.3 & 0.001 & 0.99 \\
\hline Left ureteric injury & 0 & 0.0 & 2 & 13.3 & 0.001 & 0.4 \\
\hline
\end{tabular}

This table shows that there was no statistical significant difference between study groups regarding intra-operative complications.

Table 3. Postoperative complications in the studied patients:

\begin{tabular}{|c|c|c|c|c|c|c|}
\hline \multirow{2}{*}{$\begin{array}{c}\text { Postoperative } \\
\text { complications }\end{array}$} & \multicolumn{2}{|c|}{$\begin{array}{c}\text { Open colectomy } \\
(\mathbf{n = 1 5})\end{array}$} & \multicolumn{2}{c|}{$\begin{array}{c}\text { Laparoscopic } \\
\text { colectomy }(\mathbf{n = 1 5})\end{array}$} & $\mathbf{X}^{\mathbf{2}}$ & $\mathbf{p}$ \\
\hline No complications & $\mathbf{N o}$ & $\mathbf{\%}$ & $\mathbf{N o}$ & $\mathbf{\%}$ & & $\mathbf{0 . 0 0 6 ( \mathbf { S } )}$ \\
\hline Burst abdomen & 3 & 53.5 & 15 & 100 & 6.7 & 0.2 \\
\hline Fistula & 2 & 13.3 & 0 & 0.0 & 0.5 & 0.4 \\
\hline Incisional hernia & 2 & 13.3 & 0 & 0.0 & 0.5 & 0.4 \\
\hline
\end{tabular}

This table shows that there was a statistical significant difference between study groups in postoperative complications as none of Laparoscopic colectomy patients had postoperative complications.

Table 4. Operation time in the studied patients:

\begin{tabular}{|l|c|c|c|c|}
\hline $\begin{array}{c}\text { Operation time } \\
(\text { min. })\end{array}$ & $\begin{array}{c}\text { Open colectomy } \\
(\mathbf{n}=\mathbf{1 5})\end{array}$ & $\begin{array}{c}\text { Laparoscopic colectomy } \\
(\mathbf{n = 1 5})\end{array}$ & $\mathbf{T}$ & $\mathbf{p}$ \\
\hline Range & $110.0-160.0$ & $120.0-180.0$ & 1.5 & 0.1 \\
Mean \pm SD & $135.3 \pm 17.7$ & $145.3 \pm 19.6$ & & \\
\hline
\end{tabular}

This table shows that there was no statistical significant difference between study groups regarding operation time. 
Table 5. Length of hospital stay of the studied patients:

\begin{tabular}{|l|c|c|c|c|}
\hline $\begin{array}{c}\text { Length of } \\
\text { stay (days) }\end{array}$ & $\begin{array}{c}\text { Open colectomy } \\
(\mathbf{n}=\mathbf{1 5})\end{array}$ & $\begin{array}{c}\text { Laparoscopic colectomy } \\
(\mathbf{n = 1 5})\end{array}$ & MW & $\mathbf{p}$ \\
\hline Range & $5.0-15.0$ & $4.0-8.0$ & 2.4 & $\mathbf{0 . 0 2}$ \\
Median & 6.0 & 5.0 & & $\mathbf{S}$ \\
Mean \pm SD & $7.9 \pm 3.7$ & $5.4 \pm 1.4$ & &
\end{tabular}

This table shows that there was a statistical significant difference between studied groups in Length of hospital stay as Open colectomy patients had more hospital days than Laparoscopic colectomy patients.

Fig. 1.Skin marks for port site insertion for laparoscopic left hemicolectomy.

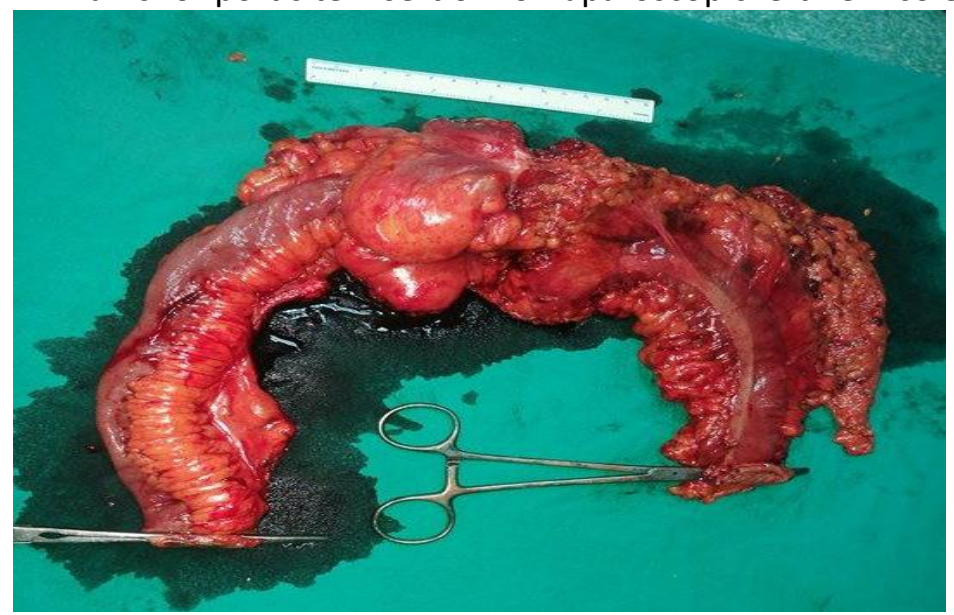

Fig. (2) Post-operative specimen after right hemicolectomy.

\section{DISCUSSION}

Surgical resection of colonic carcinoma is considered the basis of curative treatment. Over the former decade, since the first laparoscopic colon resection in 1990, a great surgical progress has been the era of colorectal cancer therapy by minimally invasive surgical techniques with its associated patient-related benefits [3]. This study highlights usage of laparoscopic techniques in resection of cancer colon and the difference between it and conventional open technique in patients with cancer colon at Zagazig university hospitals. In our study, we evaluated the efficacy of laparoscopic colectomy in achievement of proper safety margin of the resected part of the colon and proper resection of affected lymph nodes at vascular pedicle of the colon; we 
noticed that there is no statistical significant difference between study groups regarding number of affected lymph nodes. This was matched to Guerrieri $M$ et al [4]whom results clarified that there were no significant differences in the mean length of colon resected in right or left colectomy in the open Surgery versus laparoscopic surgery groups. All the margins were free of tumor invasion at the final pathology assessment, with a minimum margin of $2.0 \mathrm{~cm}$. The mean number of lymph nodes harvested during right and left colectomy did not differ significantly in the two groups [5].

In our study, the amount of blood loss was slightly less in laparoscopic colectomy in comparison to open colectomy even though, there was no statistical significant difference between the study groups regarding amount of blood loss. While Leraas H. et al [6] see that the Laparoscopic colectomy group had significantly less estimated blood loss.

In this study there were about $13.3 \%$ of cases (2/15) had post-operative fistula in open colectomy only while there were no postoperative fistula after laparoscopic colectomy. This agreed with Murray A. et al. [7], as regarding post-operative fistula, 803 from 23.865 patients $(3.4 \%), 2.8 \%$ in the laparoscopic group and $4.5 \%$ in the open group. On analysis, laparoscopic surgery was associated with reduced odds of developing an anastomotic leak. The difference in crude leak rates between the two approaches, with laparoscopic resection consistently lower, was seen across all anatomical resections.

Anastomotic leak is a potentially devastating consequence of colorectal surgery, and as such, successful attempts to reduce leak rate would have significant benefits on morbidity and mortality [7]. Laparoscopic surgery has consistently been shown to have comparable or improved short-term and oncological long-term outcomes when compared to conventional open colectomy.However, literature evaluating the effect of laparoscopic surgery on anastomotic leak rate is inconsistent and inconclusive; there has been some concern that laparoscopy is associated with increased rates of anastomotic failure [8]. Most studies, however, show no significant difference [1,7] and a minority report benefit [9].

In our study, in laparoscopic colectomy we didn't detect faecal fistula, burst abdomen, wound infection or incisional hernia. Also, in 2017, Lerass et al. [6] noticed that laparoscopic colectomy was associated with a lower rate of overall complications, specifically wound complications, urinary tract infection, venous thromboembolism complications, respiratory complications, anastomotic leak, postoperative ileus, need for blood transfusion and septic complications.

In 2018, Gavriilidis et al.[10] reported that laparoscopic Colectomy mean operative time was longer by $38 \mathrm{~min}$, and surgery involving Middle Colic Artery dissection at its origin necessarily requires surgeons with advanced laparoscopic expertise and specialized skills. This kind of surgery is surgeon and learningcurve dependent and can extend the operative time .while in our study there was no statistical significant difference between study groups regarding operative time.

According to our results there was shorter hospital stay in laparoscopic colectomy patients in comparison to open colectomy and this was agreed with Gavriilidis $\mathrm{P}$ et al. [10] that demonstrate that the length of hospital stay was significantly shorter (by four and a half days) in the LTC cohort than in the OTC cohort. This is also in line with several other studies as Hasegawa $\mathrm{H}$ et al. [11].

Also in 2016, Yerokun et al. [12]demonstrated that successfully completed laparoscopic colectomy versus open colectomy is associated with improved short term outcomes and equivalent oncologic results. Even after Conversion from planned laparoscopic colectomy to open colectomy is still associated with favorable surgical short-term outcomes such as shorter hospitalization period and improved 30-day mortality, compared to standard open colectomy[13].

In 2015, Senagore [14]demonstrated that laparoscopic colectomy has evolved to the level 
that a skilled surgeon can reproducibly provide patient-centric, high-quality, cost-efficient care for their patients requiring colorectal resections. Importantly, this surgical advancement has reduced the complication rate compared to the best results achieved with open colorectal resection. Further advancements in laparoscopic colorectal surgery should be aimed at reducing conversion rates and improving closure of the extraction site and trocar sites as these issues present the greatest opportunities for further quality and cost improvement in laparoscopic colectomy. This is due to short hospital stay and rapid recovery for patients had laparoscopic colectomy.

The rate of conversion from laparoscopic to open surgery was $8.5 \%$ (10/118) according to according to Kojima $\mathrm{M}$ et al. [15], while in our study the rate of conversion from laparoscopic colectomy to open colectomy was $13.3 \%$ $(2 / 15)$

Even in conversion from laparoscopic colectomy to open colectomy, Completeness of oncologic resection and mid-term survival were not compromised in patients experiencing conversions. Despite these results, only $45 \%$ of the patients underwent an attempted laparoscopic colectomy in the management of their colon adenocarcinoma [12].

The rate of postoperative complications were less in laparoscopic colectomy than open colectomy and there in significant difference in between two groups but this disagreed with Hasegawa $\mathrm{H}$ et al. [11] that demonstrate that There were no deaths in either group and No difference was found in terms of postoperative complications between the two groups.

\section{CONCLUSION}

Laparoscopic colectomy is considered a good and effective method for resection of colonic carcinoma as it has many benefits as early recovery, short hospital stay, early return to work and good oncological outcomes. We recommend laparoscopic resection as a gold standard for patients with colonic carcinoma.

\section{Declaration of interest}

The authors report no conflicts of interest. The authors alone are responsible for the content and writing of the paper.

Funding information None declared

\section{REFERENCES}

1) Wasserberg $\mathrm{N}$. "laparoscopic colectomy for colorectal cancer". IMAJ.2010; VOL 12.

2) Hageman, D., V. Caillet, J. Kostohryz and S. Madick."Laparoscopic-Assisted Colon Surgery." AORN Journal.2008; 88(3): 403-416.

3) Chang, G. J., \& Nelson, H. Laparoscopic colectomy. Current Gastroenterology Reports.2005; 7(5): 396-403.

4) Guerrieri, M., R. Campagnacci, A. De Sanctis, G. Lezoche, P. Massucco, M. Summa, R. Gesuita, L. Capussotti, G. Spinoglio and E. Lezoche . "Laparoscopic versus open colectomy for TNM stage III colon cancer: results of a prospective multicenter study in Italy." Surg Today .2012; 42(11): 1071-1077.

5) Hua L, Wang C, Yao K, Zhang J, Chen J, Ma W. Is the incidence of postoperative anastomotic leakage different between laparoscopic and open total mesorectal excision in patients with rectal cancer? A meta-analysis based on randomized controlled trials and controlled clinical trials. J Cancer Res Ther.2014; 10(Suppl):272-275

6) Leraas, H. J., C. T. Ong, Z. Sun, M. A. Adam, J. Kim, B. F. Gilmore, B. Ezekian, U. S. Nag, C. R. Mantyh and J. Migaly . "Hand-Assisted Laparoscopic Colectomy Improves Perioperative Outcomes Without Increasing Operative Time Compared to the Open Approach: a National Analysis of 8791 Patients." J Gastrointest Surg 2017; 21(4): 684-691.

7) Murray, A. C., C. Chiuzan and R. P. Kiran . "Risk of anastomotic leak after laparoscopic versus open colectomy." Surg Endosc .2016; 30(12): 5275-5282.

8) Krarup PM, Jorgensen LN, Andreasen $\mathrm{AH}$, Danish Colorectal Cancer Group et al. A nationwide study on anastomotic leakage after colonic cancer surgery. Colorectal Dis 2012;14(10):e661-e667

9) Kang CY, Halabi WJ, Chaudhry OO et al . A nationwide analysis of laparoscopy in high-risk colorectal surgery patients. J Gastrointest Surg .2013; 17(2):382-391

10) Gavriilidis, P. and K. Katsanos . "Laparoscopic Versus Open Transverse Colectomy: A 
Systematic Review and Meta-Analysis." World J Surg.2018; 42(9): 3008-3014.

11) Hasegawa, H., Y. Kabeshima, M. Watanabe, S. Yamamoto and M. Kitajima . "Randomized controlled trial of laparoscopic versus open colectomy for advanced colorectal cancer." Surg Endosc. 2003; 17(4): 636-640.

12) Yerokun, B. A., M. A. Adam, Z. Sun, J. Kim, S. Sprinkle, J. Migaly and C. R. Mantyh . "Does Conversion in Laparoscopic Colectomy Portend an Inferior Oncologic Outcome? Results from 104,400 Patients." J Gastrointest Surg.2016; 20(5): 1042-1048.

To Cite This Article: Mousa BR, Khalil AM, Mokhtar WL, Abdelhamid MI, Ali RM, Ashour HR. Colectomy in Patients with Colonic Carcinoma: Laparoscopic Versus Open Methods. Zumj 2020,196..203; 26(2): doi: 10.21608/zumj.2019.10198.1082. 